\title{
Xylose anaerobic conversion by open-mixed cultures
}

\author{
Margarida F. Temudo • Tania Mato • \\ Robbert Kleerebezem • Mark C. M. van Loosdrecht
}

Received: 27 August 2008 / Revised: 4 October 2008 / Accepted: 15 October 2008 / Published online: 18 November 2008

(C) The Author(s) 2008. This article is published with open access at Springerlink.com

\begin{abstract}
Xylose is, after glucose, the dominant sugar in agricultural wastes. In anaerobic environments, carbohydrates are converted into volatile fatty acids and alcohols. These can be used as building blocks in biotechnological or chemical processes, e.g., to produce bioplastics. In this study, xylose fermentation by mixed microbial cultures was investigated and compared with glucose under the same conditions. The product spectrum obtained with both substrates was comparable. It was observed that, in the case of xylose, a higher fraction of the carbon was converted into catabolic products (butyrate, acetate, and ethanol) and the biomass yield was approximately $20 \%$ lower than on glucose, 0.16 versus $0.21 \mathrm{Cmol} \mathrm{X/Cmol} \mathrm{S}$. This lower yield is likely related to the need of an extra ATP during xylose uptake. When submitted to a pulse of glucose, the population cultivated on xylose could instantaneously convert the glucose. No substrate preference was
\end{abstract}

M. F. Temudo • R. Kleerebezem $(\bowtie) \cdot$ M. C. M. van Loosdrecht Department of Biotechnology, Delft University of Technology, Julianalaan 67 ,

2628 BC Delft, The Netherlands

e-mail: r.kleerebezem@tudelft.nl

M. F. Temudo

e-mail: m.f.temudo@tudelft.nl

M. C. M. van Loosdrecht

e-mail: m.c.m.vanloosdrecht@tudelft.nl

T. Mato

Laboratory of Chemical Engineering, Faculty of Sciences,

University of A Coruña,

Alejandro de la Sota, no 1,

A Coruña 15008, Spain

e-mail: tmato@udc.es observed when glucose and xylose were fed simultaneously to the continuously operated bioreactor.

Keywords Xylose - Glucose · Fermentation · Bulk chemicals $\cdot$ Hydrogen $\cdot$ Mixed microbial population

\section{Introduction}

Lignocellulosic materials, such as wheat- or rice-straw, corn stovers, or sugar cane bagasse, are available in large amounts at a reasonable cost. Every year, about $73.9 \mathrm{Tg}$ of dry wasted crops are generated in the world (Kim 2004). During the pre-treatment, the cellulose $(35-45 \%)$ can be separated from the hemicellulose (25-40\%). Hemicellulose is a heteropolymer of hexose and pentose sugars, with Dxylose as the major constituent. Xylose is the second most abundant carbohydrate monomer after glucose in agricultural wastes. Whereas glucose can be efficiently converted to ethanol and fine chemicals, an economical application for xylose needs to be developed.

Anaerobic digestion is a widely applied process for treatment of wastewater and organic solid waste aiming at methane-rich biogas production. An alternative anaerobic process could aim for the production of intermediates in the methanogenic process from complex substrates. This can be established by specific inhibition of methane production using operational measures like non-neutral $\mathrm{pH}$-values or decreasing the solid retention time. Potentially interesting products that can be produced in this way include organic acids (acetate, butyrate, lactate, succinate), solvents (ethanol, butanol, acetone) and energy carriers like molecular hydrogen. Which mixtures of products are formed will depend on the substrate treated, the microbial population present and the operational 
conditions (Kleerebezem and van Loosdrecht 2007; Lengeler et al. 1998). An extra advantage of anaerobic processes is its association with a low biomass yield, i.e., low waste production. Fermentation of hemicellulose and hemicellulose hydrolysates is a major subject of research, mostly aimed at the production of ethanol (Sommer et al. 2004; van Maris et al. 2006). One of the problems of this process is the inability of many microorganisms to metabolize efficiently all the carbohydrates derived from hemicellulose. Moreover, the presence of mixtures of sugars may lead to a sequential utilization of the substrates: diauxic growth.

Open-mixed culture biotechnology based on natural inocula with a high microbial diversity allows for operation of bioprocesses under non-sterile conditions with no risk of strain degeneration (Kleerebezem and van Loosdrecht 2007). As opposed to pure-culture processes, mixed cultures furthermore allow for the use of continuous processing, and are capable of dealing with mixtures of substrates of variable composition. All these aspects significantly reduce the costs of mixed culture processes compared to pure-culture-based industrial fermentations. The impact of the operational conditions on glucose fermentation by mixed cultures has been studied extensively (Hawkes et al. 2007; Temudo et al. 2007; Zoetemeyer et al. 1982a; Zoetemeyer et al. 1982b). However, until now, almost no attention has been given to xylose fermentation. Recently, xylose has been reported as a suitable substrate for biohydrogen production (Calli et al. 2008; Lin et al. 2008; Lin and Cheng 2006; Lo et al. 2008) or electricity production by microbial fuel cells (Huang and Angelidaki 2008; Huang et al. 2008), in both processes by open-mixed cultures. In order to optimize the above-mentioned processes, it is of high relevance to gain knowledge on the differences that exist when fermenting glucose or xylose with open-mixed cultures.

D-Xylose is not so readily utilized as D-glucose for the production of chemicals by microorganisms (Jeffries 1983). The reason may lie on the biochemical pathways used for pentose and hexose metabolism. In most fermentative anaerobic bacteria, D-xylose has to be converted into Dxylulose-5-phosphate (X5P). This metabolite is further metabolized through either pentose phosphate pathway (PPP), or through the phosphoketolase pathway (PKP; Fig. 1). The PPP concerns a series of reactions where Dxylulose-5-phosphate is rearranged and converted into glyceraldehyde-3-phosphate (GAP; Eq. 1), an intermediate of the glucose metabolism. The phosphoketolase cleaves $\mathrm{X} 5 \mathrm{P}$ into GAP and acetyl phosphate, which is further converted into acetate and generates one ATP (Eq. 2; Tanaka et al. 2002). Despite the fact that the PPP is the most common pathway, many bacteria also have the capacity to catalyze the PKP pathway.
PPP : 3 Xylose $\rightarrow 5$ Pyruvate $+5 \mathrm{NADH}+5$ ATP

PKP : 3 Xylose $\rightarrow 3$ Pyruvate +3 NADH +3 ATP

$$
+3 \text { Acetyl }-\mathrm{P}
$$

The aim of this research is to investigate the product spectrum of xylose fermentation by mixed cultures and compare it to glucose fermentation under comparable process conditions. A relationship between the product spectrum and the type of substrate will be derived, based on generalized biochemical principles.

\section{Materials and methods}

Inoculum

The anaerobic mixed culture used as inoculum consisted of a mixture of two types of biomass, obtained from two different sources. The first inoculum came from a distillery wastewater treatment plant, Biothane in Delft, The Netherlands. This plant consists on an UASB operated at $30^{\circ} \mathrm{C}, \mathrm{pH} 6.8-7.2, \mathrm{COD}=2,500 \mathrm{mg} / \mathrm{l}$. The second inoculum was a sludge solution from a potato starch processing acidification tank in Broek op Langendijk, Smiths Food, The Netherlands. Approximately $20 \mathrm{ml}$ of each inoculum was added to the two reactors at the beginning of the experiment, and operated in batch conditions until biomass growth was observed.

\section{Reactor operation}

A continuously stirred reactor with a 3-1 capacity (21 working volume) was used (mechanical stirring $300 \mathrm{rpm}$ ). Water was recirculated through a water jacket to maintain a constant temperature of $30 \pm 1{ }^{\circ} \mathrm{C}$. The reactor medium was sparged with nitrogen gas at a flow rate of $3.6 \mathrm{vvh}$ in order to maintain anaerobic conditions. The $\mathrm{pH}$ was controlled $(8 \pm 0.1)$ by automatic titration (ADI 1030 Bio controller) with $4 \mathrm{M} \mathrm{NaOH}$ and $\mathrm{HCl}$ solutions. To prevent excessive foaming, $3 \mathrm{ml} / \mathrm{h}$ of a $3 \%$ solution of silicone antifoaming agent (BDH, England) was dosed continuously. The dilution rate was $0.12 \mathrm{~h}^{-1}$.

The reactor operated under the initial conditions (xylose $4 \mathrm{~g} / \mathrm{l}, 0.133 \mathrm{Cmol} / \mathrm{l})$ was run for 4 months, during which pulse experiments were performed. After this period, it was tested the conversion of an influent substrate concentration of $0.333 \mathrm{Cmol} / 1$ and co-fermentation of glucose and xylose (each at a final concentration of $0.067 \mathrm{Cmol} / \mathrm{l}$ ). These experiments were run for 2 weeks at each state and before starting the last experiment, the reactor was reset 
Fig. 1 Adapted scheme with the most important and expected metabolic pathways during anaerobic fermentation of xylose by mixed culture. The differences between the pentose phosphate pathway (PPP) and the phosphoketolase pathway (PKP) are indicated. The reactions indicated with $(a)$ and $(b)$, $(c)$ and $(d)$ are alternative pathways for the same product, depending mainly on the type of microorganism (Biesterveld et al. 1994; Tanaka et al. 2002)

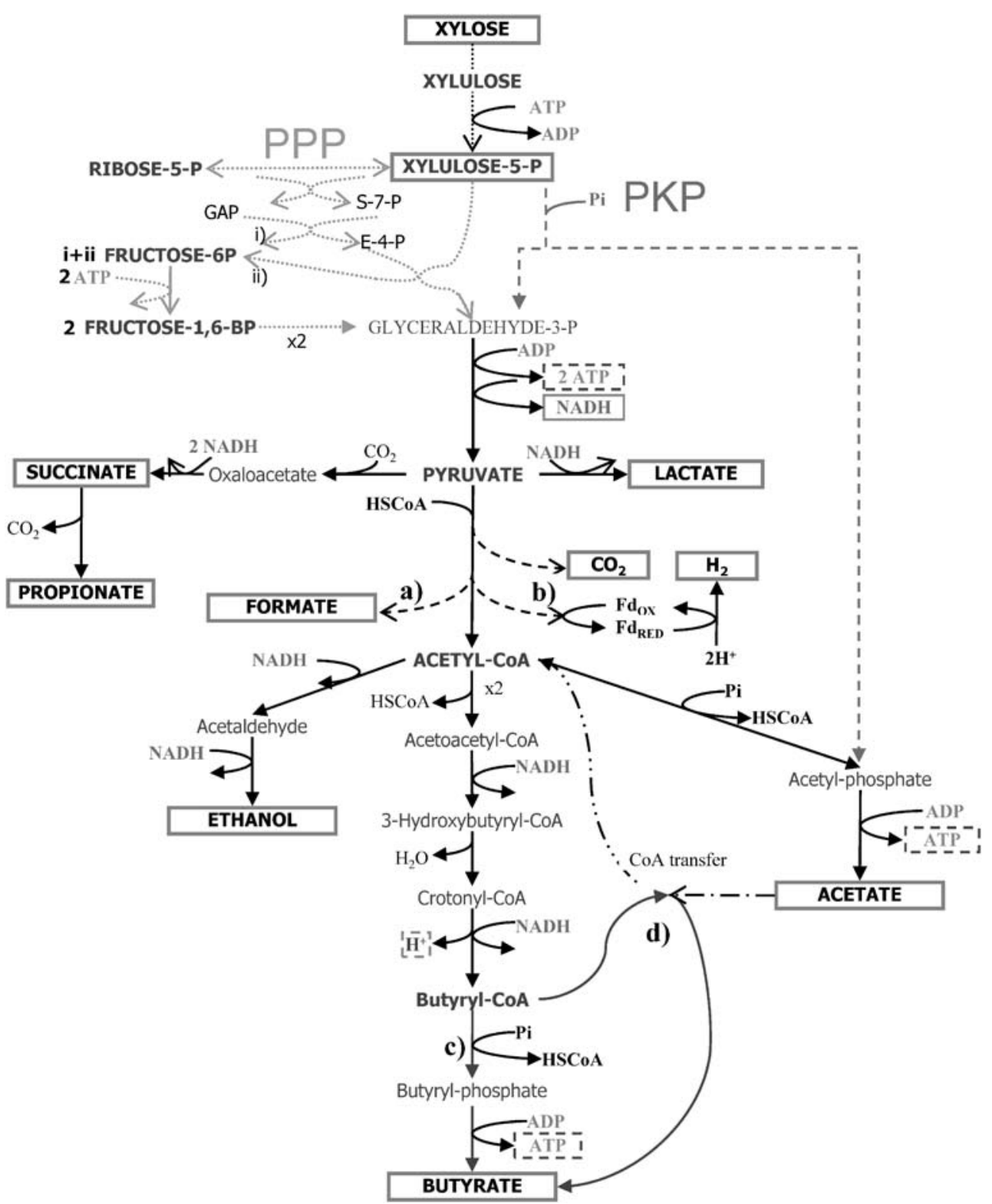

Pulse experiments

These experiments were performed in the chemostat reactor while it was in pseudo-steady state. During each experiment, the inflow pumps were switched off and a pulse of a substrate (xylose, glucose, or a mixture of glucose and xylose) and minerals was given; samples were taken and the base addition to control the $\mathrm{pH}$ was monitored. In the first experiment, two pulses of xylose were supplied, 0.067 and $0.167 \mathrm{Cmol} / \mathrm{l}$. The second pulse was supplied after xylose of the first pulse was fully converted (approximately $2 \mathrm{~h})$. Additional pulse experiments were performed with glucose $(0.083 \mathrm{Cmol} / \mathrm{l})$, and with a mixture of xylose and glucose (both $0.067 \mathrm{Cmol} / \mathrm{l}$ ). A period of at least 10 days was waited before giving another pulse to assure full recovery of the reactor performance. 


\section{System characterization}

The reactor was run in continuous mode until pseudosteady state was established, characterized by a stable product composition and biomass concentration. The off gas composition $\left(\mathrm{H}_{2}\right.$ and $\left.\mathrm{CO}_{2}\right)$ and the base added for $\mathrm{pH}$ control were monitored on-line, allowing for direct analysis of the system stability. When these three rate measurements were stable or varied within a limited range $( \pm 10 \%)$, not tending to increase or decrease, a set of samples was taken during the following week. The samples were analyzed for the concentrations of substrate and soluble organic fermentation products and the biomass concentration.

\section{Analytical methods}

Reactor broth samples were immediately filtered (Millipore membrane of $0.45 \mu \mathrm{m})$. The substrate and end products were determined and quantified. Xylose, glucose, xylitol, volatile fatty acids (acetate, propionate, butyrate, iso-butyrate, valerate, iso-valerate, and caproate), lactate, succinic acid and, formic acid were determined by HPLC, using an Aminex HPX-87H column from Bio $\operatorname{Rad}\left(T=60^{\circ} \mathrm{C}\right)$ coupled to a UV and a RI detector, while phosphoric acid $0.01 \mathrm{M}$ was used as an eluent. The alcohols analyzed were ethanol, propanol, and butanol. These analyses were performed by gas chromatography, Chromopack 9001, equipped with a flame ionization detector (FID) and a fused-silica capillary column $15 \mathrm{~m} \times 0.53 \mathrm{~mm}$ HP-INNOWAX. The column temperature was $80{ }^{\circ} \mathrm{C}$ for alcohols. The temperature of the injector and detector were $180{ }^{\circ} \mathrm{C}$ and $200{ }^{\circ} \mathrm{C}$, respectively. Furthermore, helium was used as a carrier gas.

Measurements of $\mathrm{H}_{2}$ and $\mathrm{CO}_{2}$ in the off gas were performed on-line. A gas-detection system was coupled to the bioreactor outlet and a Rosemount Analytical NGA 2000 MLT 1 Multi-component analyzer (infrared detector). Data acquisition ( $\mathrm{pH}$ and gas) was achieved with SCADA software (Sartorius BBI systems MFCS/win 2.1).

The total soluble and total chemical oxygen demand (COD) was measured in the influent and in the reactor liquid using the Dr Lange kit (1,000-10,000 $\mathrm{mg}$ COD/l). The total organic carbon (TOC) and total inorganic carbon (TIC) were measured using a Shimadzu TOC 5050A analyzer. For the total TOC and COD in samples with suspended solids, the samples were first homogenized through cell disruption in an ultrasound bath for $15 \mathrm{~s}$. The inorganic carbon was also estimated based on the Henry coefficient of $\mathrm{CO}_{2}$, the masstransfer coefficient $(\mathrm{kLa})$ of the system and carbonate equilibrium constants (Temudo et al. 2007).

The biomass dry weight was determined after filtration, according to standard methods (Greenberg et al. 1992).

The yields of the fermentation products were calculated per substrate consumed, and were corrected for the dilution factor due to dosage of base for $\mathrm{pH}$-correction. The COD and carbon balances were established based on the number of electrons and carbon atoms per mole, while assuming a standard biomass composition of $\mathrm{CH}_{1.8} \mathrm{O}_{0.5} \mathrm{~N}_{0.2}$ (Roels 1983).

\section{Calculations}

The specific substrate uptake rate $\left(-q_{\mathrm{s}}\right.$ in $\left.\mathrm{Cmol} \mathrm{S} / \mathrm{Cmol} \mathrm{X} \mathrm{h}\right)$ was determined by adjusting a linear function to the experidmental data of the substrate concentration plotted over time, considering the slope of the tangent and dividing the value obtained by the active biomass concentration at that point.

\section{Results}

Comparison between glucose and xylose conversion by mixed cultures

The bioreactor was freshly inoculated with $20 \mathrm{ml}$ of each inoculum, and was left in batch mode with either glucose or xylose until growth and microbial activity was observed. Microbial activity could be detected by the online acquisition of the gas production $\left(\mathrm{CO}_{2}\right.$ and $\left.\mathrm{H}_{2}\right)$ and the base added to maintain a constant $\mathrm{pH}$. After this adaptation period, continuous feeding was initiated. The operational performance of the reactors was characterized when a pseudosteady state was achieved. The pseudo-steady state as characterized by a constant product spectrum and biomass concentration was established after approximately 4 weeks of operation (80 volume changes).

Under substrate-limiting conditions, the product spectrum was largely comparable to glucose in the same conditions (Table 1). Compared to glucose, xylose fermentation produced more butyrate and less ethanol and the biomass yield per C mol substrate was 20\% lower. Succinate and propionate yields are not shown in Table 1 because they were always lower than $0.02 \mathrm{Cmol} / \mathrm{Cmol}^{-1}$. The carbon and electron balances showed $100 \pm 10 \%$ recovery. Other possible fermentation products such as pyruvate, malate, fumarate, valerate, iso-valerate, caproate, propanol, butanol, 2,3-butanediol, acetoin, and methylglyoxal were below the detection limit.

The yield of the acetyl-CoA-derived products (sum of acetate, ethanol and butyrate) in both reactors was close to the combined yield of formate and molecular hydrogen. This indicates that formate and hydrogen are generated upon cleavage of pyruvate into acetyl-CoA. This suggests that both substrates have been metabolized through glycolysis; the Embden Meyerhof Parnas Pathway (EMP) in case of glucose, and the pentose phosphate pathway in the case of xylose (Eq. 1). In case of a significant contribution of the phosphoketolase pathway (PKP), a substantial amount of 
Table 1 Product yields of xylose and glucose fermentation in a chemostat by mixed cultures, at $\mathrm{pH} 8$

\begin{tabular}{|c|c|c|c|}
\hline & Xylose $0.133 \mathrm{Cmol} / \mathrm{L}$ & Glucose $0.133 \mathrm{Cmol} / \mathrm{L}$ & Xylose $0.333 \mathrm{Cmol} / \mathrm{L}$ \\
\hline Dilution rate $\left(\mathrm{h}^{-1}\right)$ & $0.128 \pm 0.004$ & $0.128 \pm 0.004$ & $0.134 \pm 0.004$ \\
\hline Biomass yield $(\mathrm{Cmol} / \mathrm{Cmol})$ & $0.16 \pm 0.01$ & $0.21 \pm 0.01$ & $0.13 \pm 0.01$ \\
\hline \multicolumn{4}{|l|}{ Product yields $(\mathrm{Cmol} / \mathrm{Cmol} \mathrm{S})$} \\
\hline Acetate & $0.18 \pm 0.01$ & $0.16 \pm 0.02$ & $0.22 \pm 0.01$ \\
\hline Butyrate & $0.46 \pm 0.02$ & $0.30 \pm 0.04$ & $0.07 \pm 0.01$ \\
\hline Ethanol & $0.017 \pm 0.004$ & $0.08 \pm 0.01$ & $0.23 \pm 0.01$ \\
\hline Formate & $0.20 \pm 0.02$ & $0.22 \pm 0.01$ & $0.18 \pm 0.01$ \\
\hline $\mathrm{H}_{2}(\mathrm{~mol} / \mathrm{Cmol} \mathrm{S})$ & $0.13 \pm 0.01$ & $0.05 \pm 0.01$ & $0.06 \pm 0.01$ \\
\hline $\mathrm{H}_{2}+$ Formate $(\mathrm{mol} / \mathrm{Cmol} \mathrm{S})$ & $0.33 \pm 0.02$ & $0.27 \pm 0.01$ & $0.24 \pm 0.01$ \\
\hline Acetyl-CoA derivatives ${ }^{\mathrm{a}}(\mathrm{mol} / \mathrm{Cmol} \mathrm{S})$ & $0.33 \pm 0.02$ & $0.27 \pm 0.01$ & $0.26 \pm 0.01$ \\
\hline$Y_{\mathrm{ATP} / \mathrm{S}}\left(\mathrm{ATP} / \mathrm{Cmol} \mathrm{S}^{\mathrm{b}}\right)$ & $0.54 \pm 0.01$ & $0.42 \pm 0.01$ & $0.41 \pm 0.01$ \\
\hline$Y_{\mathrm{X} / \mathrm{ATP}}(\mathrm{X} / \mathrm{ATP}(\mathrm{g} / \mathrm{mol} \mathrm{ATP})$ & 7.6 & 12.3 & 8.0 \\
\hline
\end{tabular}

The values presented are the average of the samples (three to four) taken in the time period of one week and the respective standard deviation. ${ }^{a}$ Sum of the acetyl-CoA derivatives: acetate, butyrate and ethanol in moles of acetyl-CoA per Cmol of substrate converted

${ }^{\mathrm{b}}$ The yield of ATP was estimated based on the catabolic products: one ATP per ethanol produced, two ATP per acetate and three ATP per butyrate

acetate not accompanied by hydrogen or formate production (Eq. 2) should have been detected.

The ATP generated through catabolism was estimated by assuming that the ATP is only generated by substrate level phosphorylation (SLP) involved in each product formation pathway (Decker et al. 1970). This means, each pyruvatederived product involves a net formation of one ATP from glycolysis as written in Eq. 1; additionally, per mole of acetate and butyrate formed one more ATP is generated also via SLP. This means that in total. acetate and butyrate involve the net formation of 2 and 3 ATP, respectively. The estimated catabolic ATP yields per carbon mole of substrate converted are also given in Table 1. These values suggested that xylose catabolism was more efficient than glucose, because more ATP was generated per carbon of xylose converted ( 0.54 versus $0.42 \mathrm{~mol} \mathrm{ATP/Cmol} \mathrm{S})$. However, the measured biomass yield indicated that xylose-grown biomass had a significantly lower efficiency in ATP-utilization for biomass production compared to growth on glucose.

When the xylose concentration was increased to $0.333 \mathrm{Cmol} / \mathrm{L}$, the product spectrum shifted to more ethanol and acetate at the expense of butyrate (Table 1). Additionally, the catabolic ATP yield decreased, but the biomass yield on ATP remained in the same range of the yield at lower substrate concentration. A similar effect of increased substrate/product concentration has been observed when glucose was the substrate (Temudo et al. 2008).

\section{Characterization under substrate non-limiting conditions}

To make a clearer comparison between xylose and glucose metabolism by the selected population, three pulse experiments were conducted in the xylose-fed chemostat. Results are shown in Fig. 2. While in the chemostat reactor, the rates (growth and substrate uptake) were set by the dilution rate; during these pulse experiments, substrate non-limiting conditions were established. The calculated kinetic values and the biomass yield are given in Table 2. The initial substrate uptake rates were comparable with the chemostat reactor $(1.01,0.78$, and 0.97 compared with $0.89 \mathrm{Cmol} /$ $\mathrm{Cmol} \mathrm{X} \mathrm{h).} \mathrm{The} \mathrm{catabolic} \mathrm{products} \mathrm{were} \mathrm{the} \mathrm{same} \mathrm{as} \mathrm{obtained}$ during continuous operation: mainly butyrate and acetate.

The operational performance of the bioreactor was largely unaffected by the first xylose pulse. However, when a second pulse with the double amount of substrate was supplied, the uptake rate decreased $26 \%$. This suggests either substrate or product inhibition occurred. In terms of product concentrations, the total amount of acids increased more than $30 \%$ due to the first pulse supply of substrate.

When a glucose pulse was supplied, the culture started taking up glucose immediately. Despite the lower substrate uptake rate, the culture could make a more efficient use of this substrate as indicated by the increase in the biomass yield $(0.14 \mathrm{Cmol} / \mathrm{Cmol} \mathrm{S}$ and $0.08 \mathrm{Cmol} / \mathrm{Cmol} \mathrm{S}$ for glucose and xylose, respectively). Considering that the catabolic products were comparable, the difference in the biomass yield should be attributed to the substrate.

During the pulse with the two substrates, both substrates were simultaneously consumed in the beginning (first $2 \mathrm{~h}$ ), Fig. 2. The glucose uptake rate was approximately $20 \%$ lower than the xylose uptake rate; this difference was also observed between the single-substrate pulse experiments. However, after this period, glucose consumption almost ceased and xylose conversion decelerated. The biomass yield was also affected and decreased by $20 \%$. The product spectrum was not affected.

From these pulse experiments in the chemostat, it was confirmed that although no significant difference was observed in the catabolic products, the growth yield was enhanced when glucose was the substrate (Fig. 2). Addi- 

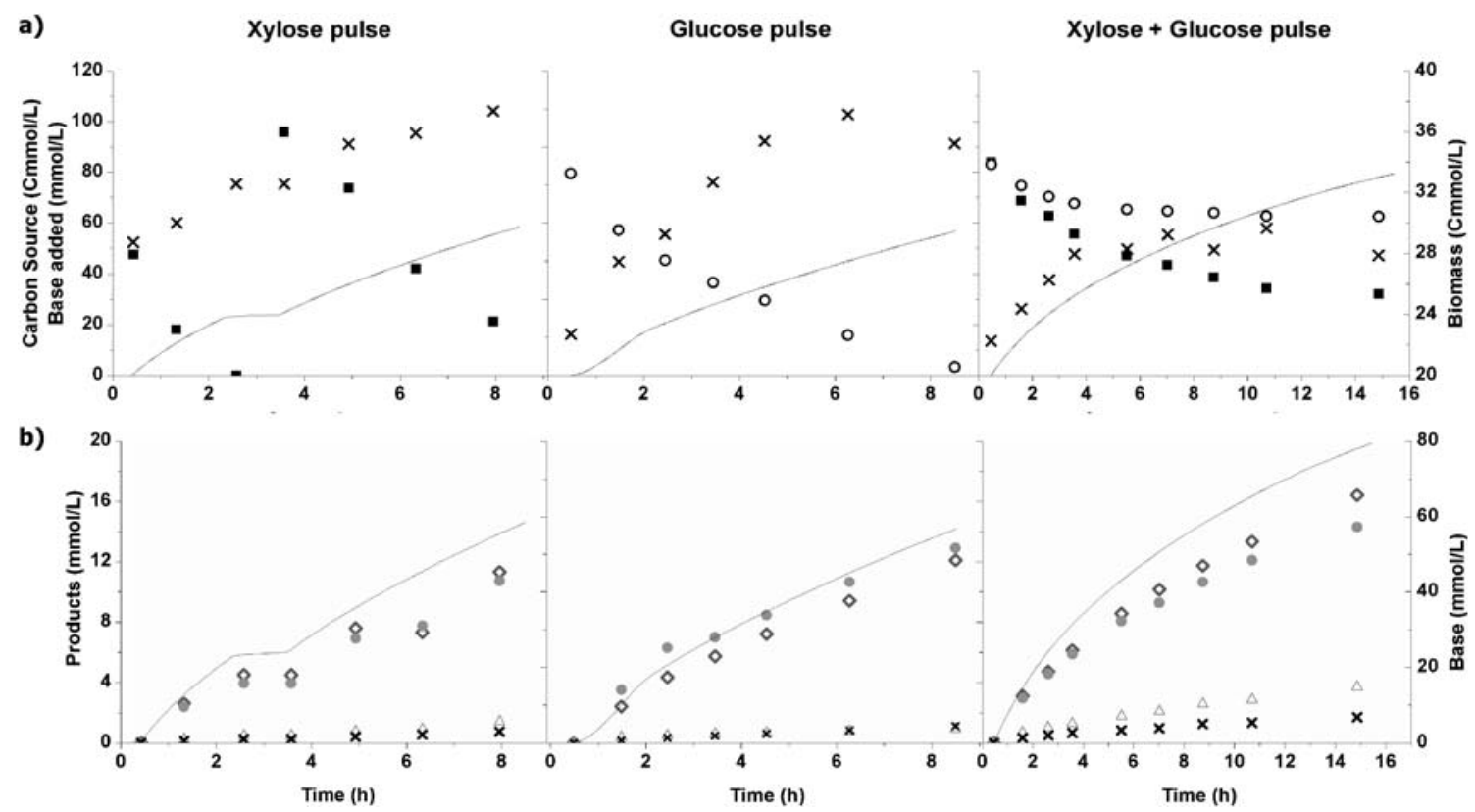

Fig. 2 Substrate pulse experiments in the chemostat previously fed with only xylose $\left(0.133 \mathrm{Cmol} / \mathrm{L}, \mathrm{pH} 8.0\right.$, dilution rate of $0.12 \mathrm{~h}^{-1}$ and temperature $30 \mathrm{C}$ ). a Substrate consumption, biomass growth and base added after xylose or/and glucose pulses were given: filled square xylose, open circle glucose, ex symbol biomass ( $\mathrm{Cmmol} / \mathrm{L})$ and solid

tionally, glucose conversion capacity was constitutively present in the microbial community growing on xylose.

Co-fermentation of glucose and xylose by mixed cultures in continuous operation

In agricultural waste streams, a mixture of sugars is present. Since a slightly different product spectrum was obtained when glucose and xylose were fermented independently, co-fermentation of xylose and glucose by the culture grown on xylose was studied. The two substrates were fed together line sodium hydroxide added to adjust the $\mathrm{pH}(\mathrm{mmol} / \mathrm{L})$. b Catabolic products and base added after xylose and glucose pulses were given: filled circle acetate, empty upright triangle propionate, diamond butyrate, ex symbol ethanol $(\mathrm{Cmmol} / \mathrm{L})$ and - sodium hydroxide added to adjust the $\mathrm{pH}(\mathrm{mmol} / \mathrm{L})$

in equal carbon amounts $(0.067 \mathrm{Cmol} / 1$ each; Fig. 3). During the first $24 \mathrm{~h}$ (three retention times), little difference could be detected. However, after 3 days, the ethanol yield increased and the butyrate yield decreased. This product spectrum seems to be an intermediate to the one obtained when the two substrates were fed separately. The yields of the other metabolic products and biomass remained almost constant.

The residual concentrations of the two substrates were below the detection limit $(0.01 \mathrm{Cmmol} / \mathrm{L})$ and no substrate preference could be detected when a xylose-glucose mixture was used.

Table 2 Kinetic parameters of the mixed microbial culture operated in continuous (substrate concentration of $0.133 \mathrm{Cmol} / \mathrm{L}$, $\mathrm{pH} 8.0$, dilution rate of $0.12 \mathrm{~h}^{-1}$ and temperature $30^{\circ} \mathrm{C}$ ) and when subjected to a pulse of a substrate (xylose, glucose and a mixture of the two substrates)

\begin{tabular}{|c|c|c|c|c|}
\hline Experiment & Substrate & Concentration $(\mathrm{Cmol} / \mathrm{L})$ & $\begin{array}{l}\text { Specific substrate uptake rate } \\
\left(-q_{\mathrm{s}}, \mathrm{Cmol} / \mathrm{Cmol} \mathrm{X} \mathrm{L} \mathrm{h}\right)\end{array}$ & $\begin{array}{l}\text { Biomass yield } \\
(\mathrm{Cmol} / \mathrm{Cmol})\end{array}$ \\
\hline \multirow[t]{2}{*}{ Continuous operation } & Xylose $^{\mathrm{a}}$ & 0.133 & 0.89 & 0.16 \\
\hline & Glucose & 0.133 & 0.62 & 0.21 \\
\hline \multirow[t]{7}{*}{ Pulse experiments } & Xylose & 1st addition 0.067 & 1.01 & 0.081 \\
\hline & & 2nd addition 0.167 & 0.55 & 0.064 \\
\hline & Glucose & 0.083 & 0.78 & 0.143 \\
\hline & Xylose and glucose & Phase $1^{\mathrm{b}}$ & & \\
\hline & & Xylose+glucose: 0.167 & 0.97 & 0.111 \\
\hline & & Xylose 0.083 & 0.56 & n.a. \\
\hline & & Glucose 0.083 & 0.41 & n.a. \\
\hline
\end{tabular}

\footnotetext{
${ }^{\text {a }}$ Average of the values determined during three days before these experiments

${ }^{\mathrm{b}}$ Phase 1 comprehends the first $3 \mathrm{~h}$ of this experiment

n.a. Not available
} 
Fig. 3 Co-fermentation of glucose and xylose by a mixed microbial culture cultivated on xylose. The arrow indicates the moment when the substrate in the medium (xylose $0.133 \mathrm{Cmol} / \mathrm{l})$ was replaced by a mixture of two substrates (glucose and xylose, both $0.067 \mathrm{Cmol} / \mathrm{L}$ ): open square molecular hydrogen, filled square formate, filled circle acetate, open circle propionate, filled upright triangle butyrate, open upright triangle ethanol and $\times$ biomass

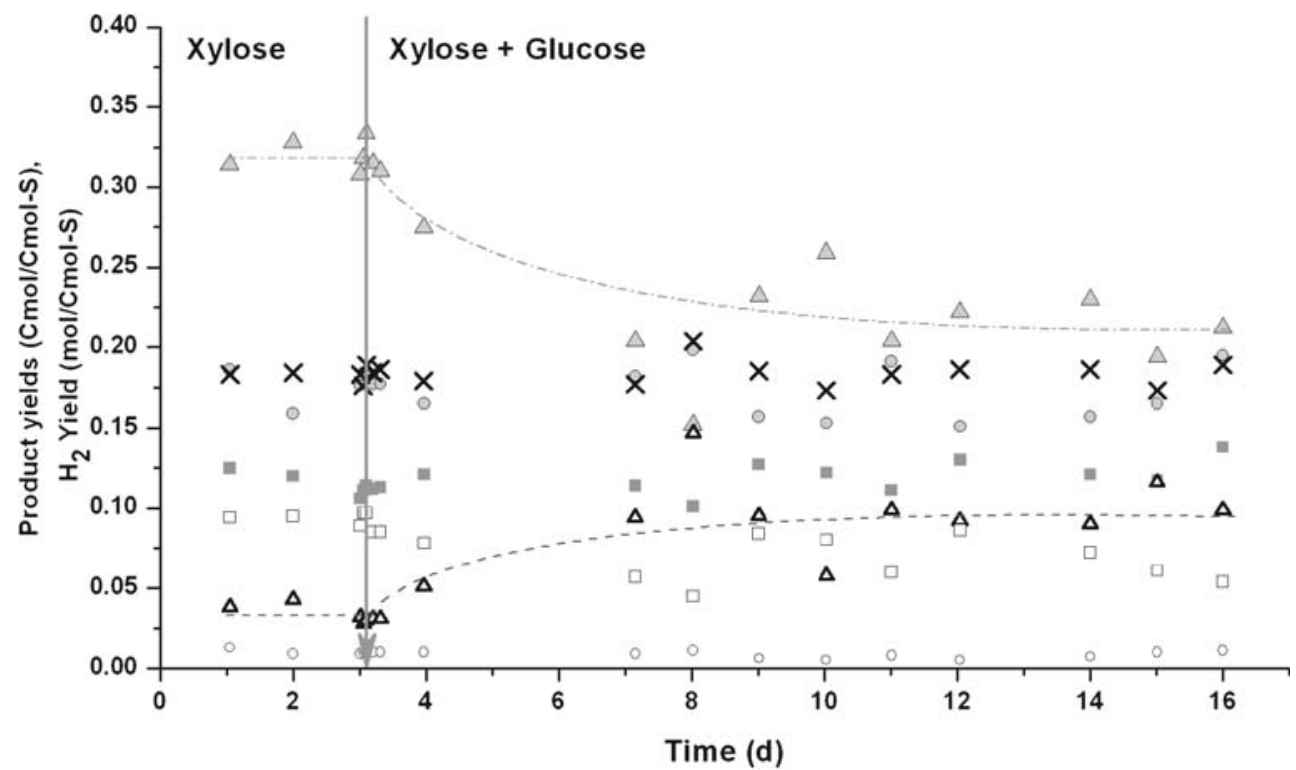

\section{Discussion}

A mixed microbial population was selected from a rich inoculum, in a CSTR fed with xylose under substratelimiting conditions. This culture was capable of converting xylose efficiently as the concentrations were kept lower than the detection limit $(0.01 \mathrm{Cmmol} / \mathrm{L})$, suggesting a high affinity for the substrate. The xylose-grown chemostat culture was also able to degrade glucose, not showing a preference for glucose or xylose when point doses of the two substrates are supplied to the bioreactor.

One of the major differences observed between mixed cultures grown on xylose and on glucose is the biomass yield on ATP $\left(Y_{\mathrm{X} / \mathrm{ATP}}\right)$, see Table 1 . The yield of catabolic products is higher for xylose, which would suggest a higher generation of ATP $\left(Y_{\mathrm{ATP} / \mathrm{S}}\right)$; however, the biomass yield is in fact higher when glucose is the substrate $\left(Y_{\mathrm{X} / \mathrm{S}}\right)$. This difference has also been observed in studies conducted with pure bacterial cultures, where the biomass yield on the catabolic ATP yield estimated $\left(Y_{\mathrm{ATP} / \mathrm{S}}\right)$ is significantly higher for glucose than for xylose (Biesterveld et al. 1994; Heyndrickx et al. 1991; Ounine et al. 1985). Furthermore, in solvent-producing bacteria, not only growth is inhibited but also the xylose uptake is affected by the solvents (Ounine et al. 1985; Qureshi et al. 2006). This is in agreement with the lower energy provided during xylose catabolism. This might be a result of different transport systems that are present in the different species (Jeffries 1983). Facilitated diffusion is the most common mechanism in yeast, the glucose transporters can also catalyze xylose uptake, but have a much lower affinity (Hamacher et al. 2002). In bacteria, however, a number of xylose-specific transporters with different affinities have been identified (Strobel 1993a, b). Of particular interest is the high affinity transporter that consists of an $\mathrm{ABC}$ protein and therefore involves one ATP consumption for each xylose transported (Ahlem et al. 1982; Hasona et al. 2004). According to genome databases (http:// www.genome.jp), this transporter is widespread over bacterial species able to metabolize xylose, e.g., in fermentative (gram-positive) microorganisms like $C$. acetobutylicum, but whether it is expressed remains unknown. In case this is the most active transporter in the microbial population selected, the catabolic ATP yield can be recalculated by considering the need of one ATP for xylose transport and one for activation inside the cell. As one molecule of pyruvate comes from $0.6 \mathrm{~mol}$ of xylose, this means that the ATP yield associated to pyruvate, as written in Eq. 1, will be affected by this value and becomes $0.4 \mathrm{~mol} \mathrm{ATP} / \mathrm{mol}$ pyruvate formed from xylose. Whereas glucose requires only one ATP for transport and activation, being the glycolytic efficiency estimated to be $1 \mathrm{~mol} \mathrm{ATP} / \mathrm{mol}$ pyruvate. Including these assumptions in our calculations, the $Y_{\mathrm{X} / \mathrm{ATP}}$ becomes $12.4 \mathrm{~g}$ $\mathrm{VSS} / \mathrm{mol}$ ATP for xylose, which is highly comparable to glucose (12.2 $\mathrm{g} \mathrm{VSS} / \mathrm{mol}$ ATP). We therefore suggest that the lower biomass yield $\left(Y_{\mathrm{X} / \mathrm{S}}\right)$ for growth on xylose compared to glucose, is related to the ATP consumption required for active xylose uptake. Such a difference has not been reported for modified yeast cells that were able to ferment xylose (Kuyper et al. 2005a), where the $Y_{\text {ATP/S }}$ remained in the same range for the two substrates.

In this study, a mixed microbial population was selected especially for xylose conversion. It was shown that even a culture that was cultivated only on xylose could immediately convert glucose (Figs. 2 and 3). Under non-limiting conditions (pulse experiment), however, the conversion of the two substrates showed some limitations. After a couple of hours, substrate conversion almost ceased. One possible explanation is that the selected population might be sensitive 
to the substrate concentration and/or increased product concentrations. Mixed substrate utilization in batch mode could be further improved by operating in a sequencing batch reactor on the two substrates (Kuyper et al. 2005b).

\section{Use of real waste streams}

During this study, all experiments were conducted with synthetic medium. The aim was to study the conversion of the two substrates under substrate-limiting and non-limiting conditions. For practical implementation of the process proposed here, experiments will need to be conducted with mixtures of substrates and real waste streams to verify the pure substrate results. In this respect, it is important to note that difficulties have been reported with the use of real waste streams; e.g., due to the presence of toxic compounds. These issues would have to be addressed before the application of a certain organic waste.

Another aspect of relevance is whether the waste streams are rich in readily biodegradable substrates or in polymers that still have to be hydrolyzed. In this situation, fermentation is not the limiting step and retention times may need to be extended, which may allow other bacteria to convert further the fermentation products by, e.g., methanogenic bacteria. This suggests the requirement to run the mixed culture fermentation process in conditions that are unfavorable for methanogens, e.g., by (periodical) lowering of the operational $\mathrm{pH}$.

Acknowledgment This work was funded by the Dutch Technology Foundation (STW), project no. DPC5904.

Open Access This article is distributed under the terms of the Creative Commons Attribution Noncommercial License which permits any noncommercial use, distribution, and reproduction in any medium, provided the original author(s) and source are credited.

\section{References}

Ahlem C, Huisman W, Neslund G, Dahms AS (1982) Purification and properties of a periplasmic D-xylose-binding protein from Escherichia coli K-12. J Biol Chem 257(6):2926-2931

Biesterveld S, Elferink S, Zehnder AJB, Stams AJM (1994) Xylose and Glucose-Utilization by Bacteroides xylanolyticus X5-1 cells grown in batch and continuous-culture. Appl Environ Microbiol 60(2):576-580

Calli B, Schoenmaekers K, vanbroekhoven KLD (2008) Dark fermentative $\mathrm{H} 2$ production from xylose and lactose-effects of on-line pH control. Int J Hydrogen Energy 33(2):522-530

Decker K, Jungerma K, Thauer RK (1970) Energy production in anaerobic organisms. Angew Chemie Int Ed 9(2):138-\&

Greenberg AE, Eaton AD, Clesceri LS (1992) Standard methods for the examination of water and wastewater, 18th edn. ChapmanHall, London

Hamacher T, Becker J, Gardonyi M, Hahn-Hagerdal B, Boles E (2002) Characterization of the xylose-transporting properties of yeast hexose transporters and their influence on xylose utilization. Microbiology-Sgm 148:2783-2788

Hasona A, Kim Y, Healy FG, Ingram LO, Shanmugam KT (2004) Pyruvate formate lyase and acetate kinase are essential for anaerobic growth of Escherichia coli on xylose. J Bacteriol 186 (22):7593-7600

Hawkes FR, Hussy I, Kyazze G, Dinsdale R, Hawkes DL (2007) Continuous dark fermentative hydrogen production by mesophilic microflora: principles and progress. Int J Hydrogen Energy 32(2):172-184

Heyndrickx M, Devos P, Deley J (1991) Fermentation of D-xylose by Clostridium butyricum Lmg-1213t1 in chemostats. Enzyme Microb Technol 13(11):893-897

Huang LP, Angelidaki I (2008) Effect of humic acids on electricity generation integrated with xylose degradation in microbial fuel cells. Biotechnol Bioeng 100(3):413-422

Huang LP, Zeng RJ, Angelidaki I (2008) Electricity production from xylose using a mediator-less microbial fuel cell. Bioresour Technol 99(10):4178-4184

Jeffries TW (1983) Utilization of xylose by bacteria, yeasts and fungi. Adv Biochem Eng Biotechnol 27:1-32

Kim S (2004) Global potential bioethanol production from wasted crops and crop residues. Biomass Bioenergy 26(4):361-375

Kleerebezem R, van Loosdrecht MCM (2007) Mixed culture biotechnology for bioenergy production. Curr Opin Biotechnol 18:207-212

Kuyper M, Hartog MMP, Toirkens MJ, Almering MJH, Winkler AA, van Dijken JP, Pronk JT (2005a) Metabolic engineering of a xylose-isomerase-expressing Saccharomyces cerevisiae strain for rapid anaerobic xylose fermentation. FEMS Yeast Res 5(4-5): 399-409

Kuyper M, Toirkens MJ, Diderich JA, Winkler AA, van Dijken JP, Pronk JT (2005b) Evolutionary engineering of mixed-sugar utilization by a xylose-fermenting Saccharomyces cerevisiae strain. FEMS Yeast Res 5(10):925-934

Lengeler JW, Drews G, Schlegel HG (1998) Biology of Prokaryotes. Blackwell, Oxford, p 955

Lin CY, Cheng CH (2006) Fermentative hydrogen production from xylose using anaerobic mixed microflora. Int $\mathrm{J}$ Hydrogen Energy 31(7):832-840

Lin C-Y, Wu C-C, Hung C-H (2008) Temperature effects on fermentative hydrogen production from xylose using mixed anaerobic cultures. Int J Hydrogen Energy 33(1):43-50

Lo Y-C, Chen WM, Hung CH, Chen SD, Chang JS (2008) Dark H2 fermentation from sucrose and xylose using H2-producing indigenous bacteria: feasibility and kinetic studies. Water Res 42(4-5):827-842

Ounine K, Petitdemange H, Raval G, Gay R (1985) Regulation and butanol inhibition of D-xylose and D-glucose uptake in Clostridium acetobutylicum. Appl Environ Microbiol 49(4):874-878

Qureshi N, Li XL, Hughes S, Saha BC, Cotta MA (2006) Butanol production from corn fiber xylan using Clostridium acetobutylicum. Biotechnol Progr 22(3):673-680

Roels JA (1983) Energetics and kinetics in biotechnology. Elsevier, Amsterdam

Sommer P, Georgieva T, Ahring BK (2004) Potential for using thermophilic anaerobic bacteria for bioethanol production from hemicellulose. Biochem Soc Trans 32:283-289

Strobel HJ (1993a) Evidence for catabolite inhibition in regulation of pentose utilization and transport in the ruminal bacterium Selenomonas ruminantium. Appl Environ Microbiol 59(1):40-46

Strobel HJ (1993b) Pentose utilization and transport by the ruminal bacterium Prevotella ruminicola. Arch Microbiol 159(5):465-471

Tanaka K, Komiyama A, Sonomoto K, Ishizaki A, Hall SJ, Stanbury R (2002) Two different pathways for D-xylose metabolism and the effect of xylose concentration on the yield coefficient of L-lactate 
in mixed-acid fermentation by the lactic acid bacterium Lactococcus lactis 10-1. Appl Microbiol Biotechnol 60(1-2):160-167

Temudo MF, Kleerebezem R, van Loosdrecht M (2007) Influence of the $\mathrm{pH}$ on (open) mixed culture fermentation of glucose: a chemostat study. Biotechnol Bioeng 98(1):69-79

Temudo MF, Poldermans R, Kleerebezem R, van Loosdrecht MCM (2008) Glycerol fermentation by mixed cultures, a Chemostat study. Biotechnol Bioeng 100(6):1088-1098

van Maris AJA, Abbott DA, Bellissimi E, van den Brink J, Kuyper M, Luttik MAH, Wisselink HW, Scheffers WA, van Dijken JP, Pronk
JT (2006) Alcoholic fermentation of carbon sources in biomass hydrolysates by Saccharomyces cerevisiae: current status. Antonie Leeuwenhoek 90(4):391-418

Zoetemeyer RJ, Arnoldy P, Cohen A, Boelhouwer C (1982a) Influence of temperature on the anaerobic acidification of glucose in a mixed culture forming part of a 2-stage digestion process. Water Res 16(3):313-321

Zoetemeyer RJ, van den Heuvel JC, Cohen A (1982b) pH Influence on acidogenic dissimilation of glucose in an anaerobic digester. Water Res 16(3):303-311 